\title{
MOTIVASI PEMANFAATAN E-LEARNING PADA GURU DI SEKOLAH KABUPATEN GOWA
}

\author{
Sutarsi Suhaeb \\ Jurusan Pendidikan Teknik Elektronika Universitas Negeri Makassar \\ Jln. daeng Tata Raya UNM Makassar \\ Sutarsi.suhaeb@unm.ic.id
}

\begin{abstract}
Abstrak
Tujuan yang ingin dicapai dalam Program Kemitraan ini adalah: (1) Guru dan siswa menggunakan internet sebagai alat komunikasi umum yang mendukung proses pembelajaran secara optimal. (2) Menggunakan moodle pembelajaran sebagai forum interaktif untuk siswa (3) Guru memiliki pengetahuan tentang cara membangun kelas e-learning berbasis moodle. Output yang diharapkan dari layanan masyarakat adalah: (1) 20 Guru memahami konsep dasar elearning sehingga mereka dapat melangkah lebih jauh dalam penerapan teknologi komputer berbasis online. (2) 20 guru termotivasi untuk menggunakan e-learning sebagai media proses pembelajaran. (3) 20 Guru dapat menerapkan e-learning sehingga siswa dapat aktif dalam mengelaborasi informasi yang diperoleh secara kreatif dan terampil tanpa dibatasi oleh waktu dan ruang. Hasil dalam implementasi layanan masyarakat terdiri dari: (1) Peserta dapat merancang kelas e-learning menggunakan moodle. (2) Peserta mampu mengelola kelas dalam proses pembelajaran menggunakan E-learning. (3) Peserta telah memiliki wawasan tentang E-learning. Kesimpulan dari kegiatan PKM ini adalah: (1) Peserta dapat merancang kelas e-learning menggunakan moodle. (2) Peserta telah mampu mengelola kelas dalam proses pembelajaran menggunakan E-learning. (3) hasil penelitian berdasarkan hasil analisis kuesioner motivasi yang telah terdistribusi, berdasarkan hasil kuesioner motivasi peserta di SMP Negeri 1 Bontonompo 1, tingkat keberhasilan dengan kategori tinggi 10 atau 100\%. Sedangkan Berdasarkan hasil kuesioner motivasi peserta di SMP Handayani, Tingkat keberhasilan dengan kategori tinggi 9 atau 90\%. Sedangkan Tingkat keberhasilannya dengan kategori sedang 1 atau 10\%. Oleh karena itu saran dari kegiatan ini adalah bahwa kegiatan ini harus terus dikembangkan dan diterapkan secara luas di antara para guru karena dapat membantu meningkatkan motivasi, efektivitas dan pembelajaran yang efisien.
\end{abstract}

Kata kunci : E-Learning, Moodle, Belajar.

\begin{abstract}
The objectives to be achieved in this Partnership Program are: (1) Teachers and students use the internet as a public communication tool that optimally supports the learning process. (2) Using moodle learning as an interactive forum for students (3) Teachers have knowledge of how to build moodle-based e-learning classes. The expected outputs from community services are: (1) 20 Teachers understand the basic concepts of e-learning so that they can go further in applying online-based computer technology. (2) 20 teachers are motivated to use e-learning as a medium for the learning process. (3) 20 Teachers can apply e-learning so that students can be active in elaborating information obtained creatively and skillfully without being limited by time and space. The results in implementing community services consist of: (1) Participants can design e-learning classes using moodle. (2) Participants are able to manage classes in the learning process using Elearning. (3) Participants already have insight into E-learning. The conclusions of this PKM activity are: (1) Participants can design e-learning classes using moodle. (2) Participants have been able to manage classes in the learning process using E-learning. (3) the results of the study are based on the results of the distributed motivation questionnaire analysis, based on the results of the participant motivation questionnaire in SMP Negeri 1 Bontonompo 1, the success rate with a high category of 10 or $100 \%$. Whereas Based on the results of the participant's motivation questionnaire in SMP Handayani, the success rate with a high category was 9 or $90 \%$. While the
\end{abstract}


success rate is in the medium category of 1 or 10\%. Therefore the suggestion from this activity is that this activity should continue to be developed and applied widely among teachers because it can help increase motivation, effectiveness and efficient learning.

Keywords: E-Learning, Moodle, Learning.

\section{PENDAHULUAN}

Kedua mitra ini terletak di kabupaten Gowa, mitra pertama yaitu SMP Negeri I Bontonompo terletak di jl. Pendidikan No.16 Tamallayang, Kec. Bontonompo. Dan mitra kedua SMP Handayani terletak dijalan Agussalim No 16 kecamatan somba opu, jumlah kelas sebanyak 5 kelas terdiri dari kelas VII,VIII, IX kurikulum yang diijadikan landasan pembuatan RPP adalah kurikulum KTSP serta strategi pembelajaran menggunakan metode konvensional.

Berdasarkan hasil survei dan wawancara kedua mitra pada pimpinan sekolah SMP, kendala utama yang dihadapi oleh para tenaga pendidik menyatakan bahwa dengan dilaksanakannya pemerataan perubahan kurikulum KTSP ke Kurikulum 2013 pada tingkat satuan pendidikan dikabupaten gowa maka diharapkan siswa aktif dalam mengelaborasi informasi yang diperoleh serta secara kreatif dan terampil sehingga guru harus terampil membuat strategi dan media dalam proses pembelajaran. Namun, Sementara ini guru masih menganut proses pembelajaran yang menerapkan sistem tradisional "teacher-centered". Dengan adanya perubahan kurikulum, "teacher-centered" akan berubah menjadi pembelajaran "Student centered" peran guru dalam pembelajaran adalah sebagai fasilitator yang bertugas sebagai perancang proses belajar. Seiring dengan perkembangan teknologi internet, guru dan siswa menggunakan internet hanya sebatas komunikasi umum tanpa memanfaatkan secara optimal dalam proses pembelajaran.

Kegiatan pemanfaatan e-learning ini menjadi salah satu solusi kongkrit dalam mendukung kegiatan pembelajaran dengan "student centered" suatu media yang membantu dan mempermudah dalam penyampaian informasi sehingga diharapkan menimbulkan rangsangan kepada peserta didik dan lebih memperluas, memperdalam informasi yang diterima. e-learning sebagai proeses pembelajaran jarak jauh dengan menggabungkan prinsip-prinsip dalam proses pembelajaran dengan teknologi (Chandrawati, 2018). Fitur e-learning juga dapat memudahkan guru mengelolah proses pembelajaran tidak hanya di ruang tertutup (kelas). Sistem e-learning digunakan sebagai sarana untuk proses belajar mengajar yang dilaksanakan tanpa harus bertatap muka secara langsung antara guru dengan peserta didik (Syahirul, 2010).

E-learning merupakan proses belajar secara efektif yang dihasilkan dengan cara menggabungkan penyampaian materi secara digital yang terdiri dari dukungan dan layanan dalam belajar (Munir. 2009).

Dalam proses pembelajaran maka konten memegang peranan penting karena langsung berhubungan dengan proses pembelajaran peserta (siswa) (Pandani., 2012). Menurut Konten merupakan obyek pembelajaran yang menjadi salah satu parameter keberhasilan e-learning melalui jenis, isi dan bobot konten (Sutanta, 2009). Sistem e-learning harus dapat:

1) Menyediakan konten yang bersifat teacher-centered yaitu konten instruksional yang bersifat prosedural, deklaratif serta terdefinisi dengan baik dan jelas;

2) Menyediakan konten yang bersifat learner- centered yaitu konten yang menyajikan hasil (outcomes) dari instruksional yang terfokus pada 
pengembangan kreatifitas dan memaksimalkan kemandirian;

3) Menyediakan contoh kerja (work example) pada material konten untuk mempermudah pemahaman dan memberikan kesempatan untuk berlatih;

4) Menambahkan konten berupa games edukatif sebagai media berlatih alat bantu pembuatan pertanyaan.

Berdasarkan analisis situasi diatas, maka dirumuskan masalah secara spesifik sebagai berikut:

1) Guru dan peserta didik menggunakan internet hanya sebagai sarana komunikasi secara umum yang kurang mendukung proses pembelajaran secara optimal.

2) Minimnya pemanfaatan moodle pembelajaran sebagai wadah interaktif bagi peserta didik.

3) Guru lebih dominan menggunakan metode pembelajaran konvensional dikarenakan memiliki pengetahuan yang minim tentang cara membuat moodle kelas e-learning.

4) Adanya perubahan kurikulum KTSP ke kurikulum 2013 membuat siswa dituntut aktif dalam mengelaborasi informasi yang diperoleh secara kreatif dan keterampil mengasah kemampuan berkolaborasi.

Dari permasalahan diatas, maka dianggap perlu adanya solusi yang dapat membantu mengatasi permasalahan yang dihadapi oleh guru. Solusi yang ditawarkan yaitu pemanfaatan E-learning sebagai bekal pengetahuan guru dan siswa dalam memanfaatkan internet secara optimal dalam proses pembelajaran, menciptakan ruang inovatif proses pembelajaran dengan memanfaatkan perkembangan teknologi.

\section{METODE PELAKSANAAN}

Berdasarkan hasil identifikasi masalah dan survey pada kedua mitra sekolah, program Kemitraan Masyrakat (PKM) akan melaksanakan kegiatan memanfaatkan e-learning sebagai sarana pembelajaran. Metode pelaksanaan yang dilakukan dalam kegiatan ini melewati beberapa tahapan.. Metode yang digunakan dalam tahap ini yaitu :

\subsection{Pelaksanaan Kegiatan E-Learning}

\section{a. Tahap awal}

Metode ceramah dan tanya jawab digunakan untuk:

1) Memberikan materi dasar dan pengenalan tentang E-learning .

2) Memberikan /menyediakan bahan berupa software yang dipakai dalam pembelajaran E-learning.

3) Menyediakan layanan server dan internet yang memadai untuk penggunaan E-learning.

4) Memberikan materi berupa cara penggunaan/pengelolahan fitur pada E-learning.

5) Menjelaskan peran dan keunggulan Elearning dalam mengelolah kelas. Peserta kegiatan memperhatikan dan mengajukan pertanyaan.

6) Menjelaskan cara mengakses Elearning dengan mendaftarkan akun, Peserta kegiatan memperhatikan dan mengajukan pertanyaan.

b. Tahap proses

1) Menjelaskan cara membuka kelas pembelajaran baru oleh pengajar dan mendaftar dikelas yang telah tersedia bagi peserta didik. Peserta kegiatan memperhatikan dan mengajukan pertanyaan.

2) Menjelaskan cara memulai pembelajaran dan pemberian tugastugas di E-learning serta cara memberikan ujian ke peserta didik dengan memaksimalkan penggunakan fitur-fitur yang ada pada E-learning. Peserta kegiatan memperhatikan dan mengajukan pertanyaan.

3) Metode pemberian tugas digunakan untuk: Pemberian tugas kepada peserta untuk memulai menggunakan elearning, mengelolah kelas berdasarkan posisinya (pendidik atau peserta didik), serta dapat 
memaksimalkan penggunaan fiturfitur yang ada di elearning.

4) Metode simulasi dan demonstrasi digunkan untuk: Mendemostrasikan cara memulai untuk mengakses elearning. Peserta mengikuti dan melakuan apa yang didemonstrasikan oleh pemateri.

5) Mendemonstrasikan cara membuat atau mendaftar di elearning sebagai pendidik/peserta didik. Peserta mengikuti dan melakuan apa yang didemonstrasikan oleh pemateri.

6) Mendemonstrasikan cara memulai pembelajaran baru, pemberian tugas, pemberian ujian, serta memeriksa hasil ujian. Peserta mengikuti dan melakuan apa yang didemonstrasikan oleh pemateri.

7) Metode praktek digunakan untuk:

Melaksanakan praktek mulai dari mengakses elearning, mendaftar atau membuat akun baru, mengelolah kelas, sampai memerikasi hasil ujian akhir. Pelaksanan mendampingi peserta pada waktu praktek.

\section{c. Tahap evaluasi akhir}

Metode monitoring dan evaluasi, melakukan pemeriksaan terhadap hasil praktikum yang dilakukan oleh peserta, selanjutnya dilakukan pendampingan pada peserta dalam penerapan dikelas dan memberikan bimbingan jika masih ada yang belum terampil dan kompeten. Kemudian memberikan kuisioner kepada peserta untuk mengetahui hasil motivasi. Kemudian menganalisis kuisioner motivasi sebagai berikut :

\subsection{Analisis Kuisioner Motivasi.}

Untuk mengetahui peningkatan motivasi dalam kegiatan pembelajaran elearning dapat dihitung dengan menggunakan formula sebagai berikut (Anas Sudijono, 2010) :

$$
\begin{aligned}
& \mathrm{P}=\frac{f}{N} \times 100 \% \\
& \text { Information : } \\
& \text { P: Persentase } \\
& \text { f: Banyaknya skor } \\
& \text { N: Skor ideal }
\end{aligned}
$$

Keseluruhan hasil penelitian akan diklasifikasikan ke dalam bentuk penilaian, menggunakan kriteria berikut: Tabel 3.1. Kriteria Penilaian untuk Pengamatan Kegiatan e-learning.

\begin{tabular}{|c|l|}
\hline Level kesuksesan & Kategori \\
\hline $85-100 \%$ & Sangat tinggi \\
\hline $69-84 \%$ & Tinggi \\
\hline $53-68 \%$ & sedang \\
\hline $37-52 \%$ & Cukup \\
\hline $20-36 \%$ & Kurang \\
\hline
\end{tabular}

Sumber : (Sugiono, 2008)

\section{HASIL DAN PEMBAHASAN}

Implementasi pembelajaran elearning dalam kelompok guru di Kabupaten Gowa dilakukan dalam 4 pertemuan untuk masing-masing mitra sekolah. Fase dalam pelaksanaan kegiatan ini terdiri dari tiga fase, yaitu evaluasi tahap awal, fase evaluasi proses dan evaluasi tahap akhir. 2 pertemuan diadakan pada tahap awal dan proses, 2 pertemuan berikutnya diadakan pada tahap akhir evaluasi dan bantuan.

\section{a. Tahap Awal}

Tahap awal merupakan kegiatan pertama, pembicara memberikan materi tentang karakteristik, fungsi E-learning, cara menggunakan / mengelola fitur, peran dan keuntungan E-learning dalam mengelola kelas. Modul didistribusikan kepada peserta kegiatan untuk memfasilitasi praktik kegiatan. Kemudian sesi tanya jawab antara peserta dan pembicara.

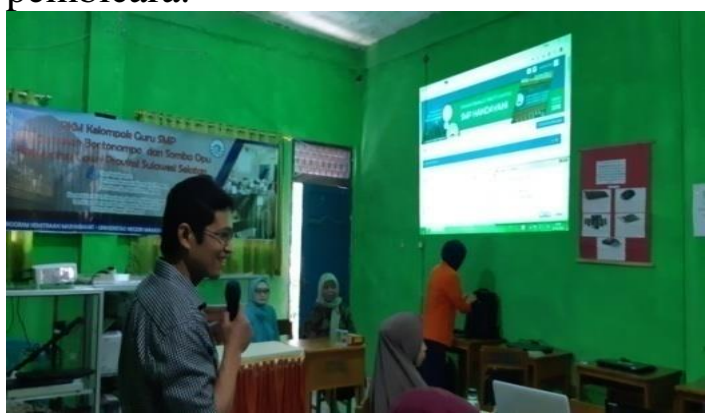

Gambar 1. Penyediaan bahan

pembelajaran tentang E-learning oleh pembicara di Sekolah Menengah

Handayani

\section{b. Tahap proses}




\begin{abstract}
Evaluasi tahap proses adalah proses implementasi kegiatan pembelajaran e-learning. Pembicara menunjukkan tahapan kegiatan dan peserta guru mensimulasikan e-learning. Tahapan berikut adalah langkah-langkah menggunakan E-learning.
\end{abstract}

1. Akses E-learning dengan mendaftarkan akun.

Dalam kegiatan E-learning, penyaji mendemonstrasikan cara mengakses dan menghubungkan Elearning. Kemudian peserta mensimulasikan apa yang telah didemonstrasikan.

2. Mendaftar sebagai pendidik dan siswa

Dalam kegiatan e-learning, pembicara menunjukkan bagaimana membuat akun sebagai guru dan mendaftarkan siswa di kelas yang tersedia kemudian peserta mensimulasikan apa yang telah di demonstrasikan.

3. Masukkan materi pembelajaran di kursus (kelas) E-learning.

Dalam kegiatan pembelajaran elearning, penyaji mendemonstrasikan bagaimana memasukkan bahan belajar atau bahan ajar dalam kursus e-learning (kelas). Bahan ajar termasuk file (PDF, Doc, PPTX, dll.), Folder, IMS, Label, Halaman, Url. Sehingga bahan ajar yang telah diunggah dapat diakses oleh siswa untuk proses pembelajaran.

4. Masukkan tugas - tugas Elearning dalam kursus (kelas).

Kegiatan belajar e-learning, penyaji mendemonstrasikan cara memasukkan tugas dalam bentuk pertanyaan, persiapan makalah, dan sebagainya. Selanjutnya, tugas dikumpulkan dengan mengunggah fasilitas yang disediakan di bagian pengiriman tugas. Jenis file yang dapat dikirim termasuk dokumen kata, speedsheet, gambar, klip audio dan video.
5. Membuat obrolan (Obrolan) di Kursus E-learning.

Dalam kegiatan pembelajaran elearning, pembicara menunjukkan bagaimana membuat obrolan (obrolan) sebagai tempat untuk berdiskusi secara real-time melalui web, untuk didiskusikan secara terus menerus antara guru dan siswa atau siswa dengan siswa.

6. Kelola fitur Quis sebagai ujian pada e-learning

Dalam penggunaan e-learning, penyaji mendemonstrasikan bagaimana mendesain kumpulan pertanyaan yang berisi beberapa choise, true false, dan pertanyaan jawaban singkat dalam kursus (kelas) E-learning dengan fitur. Pertanyaanpertanyaan ini akan disimpan di bank soal yang dapat dikategorikan dan digunakan kembali.

7. Mendaftarkan siswa sebagai siswa di kelas E-learning

Dalam kegiatan pembelajaran elearning, Penyaji mendemonstrasikan cara mendaftarkan siswa sebagai siswa di kelas e-learning.

8. Memeriksa hasil ujian siswa yang telah menjawab.

Dalam penggunaan kegiatan elearning, pembicara memperagakan cara memeriksa ujian siswa yang telah menjawab kursus (kelas) e-learning.

Berikut ini adalah gambar proses simulasi pembelajaran berbasis elearning.

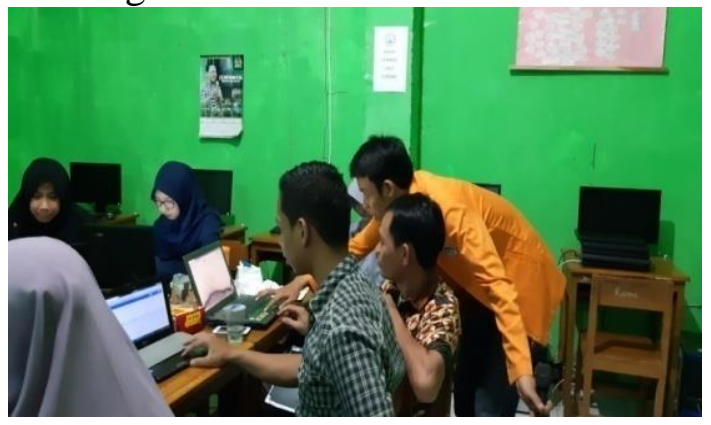

Gambar 3. Peserta dalam kegiatan mensimulasikan cara mengakses Elearning dengan mendaftarkan akun pada tahap proses. 
c. Hasil Kuisioner Motivasi Guru.

1) Berikut ini adalah kuesioner motivasi untuk guru di Sekolah Menengah Umum Bontonompo 1.

Tabel 3.1. rekapitulasi hasil kuesioner SMP Negeri 1 Bontonompo 1.

\begin{tabular}{|l|l|l|l|}
\hline $\begin{array}{l}\text { Kategori } \\
\text { sukses }\end{array}$ & Kategori & $\begin{array}{l}\text { Frekue } \\
\text { nsi }\end{array}$ & $\begin{array}{l}\text { Persen } \\
\text { tase } \%\end{array}$ \\
\hline $85-100 \%$ & Sangat Tinggi & 0 & $0 \%$ \\
\hline $69-84 \%$ & Tinggi & 10 & $100 \%$ \\
\hline $53-68 \%$ & Sedang & 0 & $0 \%$ \\
\hline $37-52 \%$ & Cukup & 0 & $0 \%$ \\
\hline $20-36 \%$ & Kurang & 0 & $0 \%$ \\
\hline
\end{tabular}

Berdasarkan hasil kuesioner motivasi peserta di SMP Negeri 1 Bontonompo 1, tingkat keberhasilan dengan kategori tinggi 10 atau $100 \%$.

2) Mengikuti tingkat motivasi guru

Sekolah Menengah Handayani.

Tabel 3.2. Rekapitulasi hasil kuesioner SMP Handayani .

\begin{tabular}{|l|l|l|l|}
\hline $\begin{array}{l}\text { Kategori } \\
\text { sukses }\end{array}$ & Kategori & $\begin{array}{l}\text { Frekue } \\
\text { nsi }\end{array}$ & $\%$ \\
\hline $85-100 \%$ & Sangat Tinggi & 0 & $0 \%$ \\
\hline $69-84 \%$ & Tinggi & 9 & $90 \%$ \\
\hline $53-68 \%$ & Sedang & 1 & $10 \%$ \\
\hline $37-52 \%$ & Cukup & 0 & $0 \%$ \\
\hline $20-36 \%$ & kurang & 0 & $0 \%$ \\
\hline \multicolumn{7}{|c|}{ Berdasarkan kuesioner }
\end{tabular}

motivasi peserta di SMP Handayani, Tingkat keberhasilan dengan kategori tinggi 9 atau 90\%. Sedangkan Tingkat keberhasilannya dengan kategori sedang 1 atau $10 \%$.

\section{KESIMPULAN}

Berdasarkan tahapan yang dilakukan selama 4 pertemuan di masing-masing sekolah mitra. Dari hasil pengabdian masyarakat di SMP Handayani dan SMP Negeri 1 Bontonompo, dengan memberikan pengetahuan dan keterampilan yang dapat digunakan oleh guru di sekolah mitra. Kegiatan pembelajaran e-learning ini memenuhi output atau target peserta kegiatan, yaitu:

1. Peserta telah mampu mengelola kelas dalam proses belajar menggunakan e-leaning.
2. Peserta telah memiliki wawasan tentang manajemen E-learning.

3. Berdasarkan hasil kuesioner motivasi peserta di SMP Negeri 1 Bontonompo 1, tingkat keberhasilan dengan kategori tinggi 10 atau $100 \%$. Sedangkan Berdasarkan hasil kuesioner motivasi peserta di SMP Handayani, Tingkat keberhasilan dengan kategori tinggi 9 atau $90 \%$. Sedangkan Tingkat keberhasilannya dengan kategori sedang 1 atau 10\%.

\section{DAFTAR PUSTAKA}

Chandrawati. Pengertian E-Learning, (online),

(http://www.Kajian.pustaka.com/pe ngertian-karakteristik-dan-manfaat elearning.html, (diakses 7 Juli 2018).

Munir. 2009. Pembelajaran Jarak Jauh Berbasis Teknologi Informasi Dan Komunikasi, Bandung: Alfabeta.

Pandani. Cara membuat daftar hadir siswa di html,(online).(http;//pustaka.pandan i.web.id/2012/12/cara- membuatdaftar-hadir-siswa-di.html) (diakses pada 06 juni 2017).

Sugiono. Metode penelitian Kuantitatif dan kualitatif, Bandung : Alfabeta. 2011.

Sutanta, Edhy. Konsep dan Implementasi E-Learning (Studi Kasus Pengembangan E-Learning di SMAN 1 Sentolo Yogyakarta.2009.

Syahirul,alim. Membangun e-learning berbasis internet menggunakan moodle 1.5.9 di SMA Negeri 1 Sidayu Gresik. Skripsi tidak diterbitkan, Malang; Universitas Negerei Malang . 2010. 